\title{
HUBUNGAN ANTARA KANDUNGAN SILIKA DENGAN KELIMPAHAN DIATOM BENTHIK DI SEPANJANG SUNGAI PELUS KABUPATEN BANYUMAS
}

\author{
Siti Umiatun, Carmudi, Christiani
}

Fakultas Biologi, Universitas Jenderal Soedirman, Jalan dr. Suparno 63 Purwokerto 53122

\section{A B S T RA C T}

Silica is an element that is useful to the organism especially Diatoms (Chrysophyta: Bacillariophyceae). The sources of Silica in waters derive from weathering rock-containing silica. Diatoms are a phytoplankton that able to live as a phytobenthos distributed globally in all types of waters. The purpose of this study was to determine; the silica content, the abundance of diatoms, and the relationship between the content of silica and the abundance of diatoms in the Pelus River Banyumas. This research was conducted as a survey and samples were collected using composite sampling technique at 5 stations. Samples were collected three times with 2 weeks intervals. Two main parameters (diatoms abundance and silica content) and ten supporting parameters (temperature, current velocity, pH, DO, BOD, COD, TSS, TDS, nitrate, and ortofosfat of waters) were measured. Data of analysis calculated in this study including regression correlation analysis to determine the relationship of the silica content and the abundance of diatoms. The silica concentration in the Pelus River waters varies between 112.48-175.00 mg.l-1 with an average of $146 \mathrm{mg}^{-1} \mathrm{l}^{-1}$. The total abundance of benthic diatoms was 44,442 ind.cm-2 The highest diatoms abundance was at station II $\left(11,128\right.$ ind. $\left.\mathrm{cm}^{-2}\right)$, the lowest was at Station IV $\left(6,828\right.$ ind.cm- $\left.{ }^{-2}\right)$. The relationship between silica contained in the waters and abundance of diatoms indicated by the value of R2 (coefficient of determination) by 0.38 or $38 \%$. The abundance of Diatoms are affected $62 \%$ by the available silica in the environment, and the rest $38 \%$ e rest are determined by other factors.

KEY WORDS: Pelus River, sillica, diatoms abundance

Penulis korespondensi: SITI UMIATUN | email: sitiumiatun10081991@gmail.com

\section{PENDAHULUAN}

Sungai merupakan jenis perairan dengan sistem terbuka, yang sangat tergantung pada keadaan lingkungan sekitarnya. Sungai Pelus merupakan salah satu sungai yang bervariasi dalam pemanfaatannya oleh penduduk, seperti perikanan, mandi, cuci, dan kakus yang dapat dijumpai dari daerah hulu sampai hilir. Akibat kegiatan manusia di sekitar perairan Sungai Pelus dapat mempengaruhi kualitas fisik, kimia yang selanjutnya akan mempengaruhi organisme dalam perairan.

Salah satu organisme perairan yang mempunyai peranan penting adalah diatom. Diatom merupakan produsen primer yang cukup melimpah dan diperlukan sebagai pakan alami yang banyak ditemukan diperairan tawar maupun perairan laut. Diatom merupakan kosmopolitan spesies yang terdistribusi secara luas di seluruh lingkungan akuatik bahkan pada lingkungan darat yang terendam secara berkala seperti permukaan batuan, beberapa jenis tumbuhan dan binatang (Aprisanti et al., 2013).

Ciri khas diatom ditunjukkan dengan adanya pahatan tertentu pada dinding selnya yang terdiri dari silika, memiliki ketahanan yang tinggi terhadap tekanan lingkungan. Silika merupakan elemen yang dibutuhkan diatom terutama untuk pembentukan dinding selnya. Silika ini diambil oleh diatom dalam bentuk yang terlarut dalam air, yaitu sebagai $\mathrm{Si}(\mathrm{OH})_{4}$. Berbagai jenis diatom memerlukan silika dalam jumlah yang berbeda-beda, akibatnya saat terjadi variasi kandungan silika yang terlarut dalam air maka dapat terjadi suksesi diatom, jadi perubahan kandungan silika merupakan salah satu faktor yang menyebabkan suksesi diatom (Werner, 1977).

Berdasarkan latar belakang tersebut maka muncul permasalahan antara lain berapakah kandungan silika di Sungai Pelus Kabupaten Banyumas, berapakah kelimpahan diatom disepanjang Sungai Pelus Kabupaten Banyumas, dan bagaimana hubungan antara kandungan silika dan kelimpahan diatom di Sungai Pelus Kabupaten Banyumas. Tujuan dari penelitian ini adalah untuk mengetahui kandungan silika yang didapat di Sungai Pelus Kabupaten Banyumas, kelimpahan diatom disepanjang Sungai Pelus Kabupaten Banyumas, dan hubungan antara kandungan silika dan kelimpahan diatom di Sungai Pelus Kabupaten Banyumas.

\section{MET ODE}

Penelitian ini dilaksanakan dengan menggunakan metode survei. Teknik pengambilan sampel dilakukan secara acak terpilih pada 5 stasiun penelitian yang ditentukan berdasarkan rona lingkungan. Pengambilan sampel diulang sebanyak 3 kali dengan interval waktu 2 minggu. Setiap stasiun dilakukan pengambilan sampel pada 3 titik, yaitu daerah tepi kiri, tengah dan tepi kanan di komposit. Sampel diatom diambil 3 kali ulangan pada setiap titik. Variabel penelitian terdiri dari variabel tergantung yaitu kelimpahan Diatom dan variabel bebas yaitu kandungan silika. Parameter yang diamati dalam penelitian ini meliputi parameter utama dan parameter pendukung. Parameter utama yaitu jumlah jenis dan jumlah individu Diatom. Parameter pendukung yaitu parameter fisika-kimia perairan yang meliputi suhu, kedalaman, kecepatan arus, penetrasi cahaya, pH, DO, BOD, COD, TSS, TDS, CO2 bebas, nitrat, nitrit, ortofosfat, ammonia dan silika. 
Tabel 1. Deskripsi Lokasi Penelitian

\begin{tabular}{|c|c|c|c|}
\hline \multicolumn{2}{|c|}{ No Stasiun } & Lokasi/Rona Lingkungan & Koordinat Lokasi dan Ketinggian \\
\hline 1 & I & $\begin{array}{l}\text { Telaga Sunyi Kecamatan Baturaden merupakan daerah hulu sungai } \\
\text { dengan kondisi lingkungan berupa hutan, perladangan dan pemukiman }\end{array}$ & $\begin{array}{l}07^{\circ} 18^{\prime} 29.0^{\prime \prime} \text { LS dan 109० 14'30.1" BT } \\
\text { Ketinggian } 691 \mathrm{~m} \mathrm{dpl}\end{array}$ \\
\hline 2 & II & $\begin{array}{l}\text { Desa Pandak Kecamatan Baturaden dengan kondisi lingkungan sekitar } \\
\text { berupa pemukiman, persawahan dan perikanan. }\end{array}$ & $\begin{array}{l}07^{\circ} 23^{\prime} 38.5^{\prime \prime} \text { LS dan } 109^{\circ} 14^{\prime} 54.2^{\prime \prime} \mathrm{BT} \\
\text { Ketinggian } 117 \mathrm{~m} \mathrm{dpl}\end{array}$ \\
\hline 3 & III & $\begin{array}{l}\text { Desa Ledug Kecamatan Kembaran dengan kondisi lingkungan sekitar } \\
\text { berupa pemukiman dan persawahan }\end{array}$ & $\begin{array}{l}07^{\circ} 24^{\prime} 598^{\prime \prime} \text { LS dan } 109^{\circ} 15^{\prime} 58.3^{\prime \prime} \mathrm{BT} \\
\text { Ketinggian } 45 \mathrm{~m} \mathrm{dpl}\end{array}$ \\
\hline 4 & IV & $\begin{array}{l}\text { Kecamatan Sokaraja dengan kondisi lingkungan sekitar berupa } \\
\text { pemukiman dan perindustrian (pertokoan). }\end{array}$ & $\begin{array}{l}07^{\circ} 28^{\prime} 08.4^{\prime \prime} \text { LS dan } 109^{\circ} 18^{\prime} 13.8^{\prime \prime} \mathrm{BT} \\
\text { Ketinggian } 31 \mathrm{~m} \mathrm{dpl}\end{array}$ \\
\hline 5 & V & $\begin{array}{l}\text { Desa Pajerukan Kecamatan Kalibagor dengan kondisi lingkungan } \\
\text { sekitar berupa pemukiman dan persawahan. }\end{array}$ & $\begin{array}{l}07^{\circ} 28^{\prime} 33.1^{\prime \prime} \text { LS dan } 109^{\circ} 19^{\prime} 03.6^{\prime \prime} \mathrm{BT} \\
\text { Ketinggian } 31 \mathrm{~m} \mathrm{dpl}\end{array}$ \\
\hline
\end{tabular}

Pengambilan sampel air Sungai Pelus untuk pengukuran $\mathrm{O}_{2}$ dilakukan menggunakan botol winkler dan dijaga agar udara tidak masuk kedalam botol. Pengukuran $\mathrm{O}_{2}, \mathrm{pH}$, suhu, penetrasi cahaya, kedalaman, substrat dasar, serta kuat arus dilakukan secara insitu. Pengukuran secara eksitu dilakukan dengan pengambilan sampel menggunakan jerigen volume 2 L kemudian diawetkan menggunakan cool box selanjutnya dibawa ke Laboratorium untuk pengukuran kandungan $\mathrm{BOD}_{5}, \mathrm{COD}$, TSS, TDS, $\mathrm{CO}_{2}$ bebas, nitrat, nitrit, amonia, silika dan orthofosfat.

Pengambilan sampel diatom dilakukan dengan cara mengambil sampel diatom pada substrat dasar di setiap stasiun dengan ukuran 20 × $20 \mathrm{~cm}$. Disiapkan ember yang berisi aquades $1 \mathrm{~L}$, diambil substrat pasir dimasukkan ke dalam ember, kemudian disaring menggunakan saringan bertingkat. Air hasil saringan substrat pasir ditampung di dalam ember dan disaring menggunakan plankton-net. Air yang tertampung dalam plankton-net dipindahkan ke dalam botol sampel plankton dan diberi formalin $40 \%$ hingga konsentrasinya menjadi $4 \%$ dan diberi lugol sebanyak 2-3 tetes (APHA, 1992). Formalin 4\% diproleh dengan menggunakan rumus sebagai berikut:

$$
\mathrm{V}_{1} \times \mathrm{N}_{1}=\mathrm{V}_{2} \times \mathrm{N}_{2}
$$

Keterangan:

$\mathrm{V}_{1}=$ Volume botol sampel

$\mathrm{N}_{1}=$ konsentrasi formalin yang diinginkan (4\%)

$\mathrm{V}_{2}=$ volume formalin yang ditambahkan

$\mathrm{N}_{2}=$ konsentrasi formalin yang ada (40\%)

Sampel diatom diambil dengan pipet tetes kemudian diteteskan ke dalam gelas obyek sebanyak 1 tetes dan diamati dibawah mikroskopuntuk identifikasi dengan perbesaran 400x diulang sebanyak 3 kali. Pengamatan untuk menghitung kelimpahan diatom menggunakan perbesaran 100x. Diatom yang ditemukan diidentifikasi dengan menggunakan buku Sachlan (1982), Davis (1955) dan Thompson (1959). Kemudian hasil perhitungan dikonversikan ke dalam rumus kelimpahan berdasarkan modifikasi dari "Inverted Microscope Method Counts" (APHA, Standard Method for Examination of Water and Waste Water, 1989). Perhitungan kelimpahan menggunakan rumus sebagai berikut:

$$
\frac{\text { Organisme }}{\mathrm{mm}^{2}}=\frac{\mathrm{n} \times \mathrm{At} \times \mathrm{Vt}}{\mathrm{Ac} \times \mathrm{Vs} \times \mathrm{As}}
$$

Keterangan:

$\mathrm{n} \quad=$ Jumlah organisme yang diamati

At $=$ Luasan cover glass $20 \times 20 \mathrm{~mm}\left(400 \mathrm{~mm}^{2}\right)$

$\mathrm{Vt}=$ Volume air dalam botol penampung $(145 \mathrm{ml})$

Ac $=$ Luas lapang pandang $\left(1,11279 \mathrm{~mm}^{2}\right)$

Vs = Volume air dalam object glass $(0,045 \mathrm{ml})$

As $=$ Luas substrat $\left(\mathrm{mm}^{2}\right)$
Suhu udara dan suhu air diukur dengan menggunakan termometer. Pengukuran suhu udara dilakukan dengan termometer pada udara bebas. Suhu air diukur dengan cara mencelupkan termometer ke dalam perairan selama 1 menit, setelah angkanya konstan lalu dicatat.

Pengukuran kedalaman menggunakan tongkat berskala, tongkat dicelupkan pada perairan dan dilihat permukaan perairan pada skala tongkat dan dicatat.

Penetrasi cahaya diukur dengan metode visual, menggunakan Sechi disk yang diikat dengan tali berskala 1 cm (APHA, 1992). Sechi disk diturunkan ke dalam badan air sampai tidak nampak, kemudian dicatat kedalamannya dan didapat sebagai nilai x. Sechi disk diturunkan ke dalam badan air, kemudian diangkat perlahan hingga mulai nampak lagi, lalu dicatat sebagai nilai y. Besar nilai penetrasi cahaya matahari dihitung dengan rumus sebagai berikut.

$$
\text { Penetrasi cahaya }=\frac{x+y}{2} \mathrm{~cm}
$$

Keterangan :

$\mathrm{x}=$ jarak saat Keping Secchi tidak terlihat oleh mata

$\mathrm{y}=$ jarak saat Keping Secchi terlihat lagi oleh mata

Pengamatan subsrat dasar dilakukan secara visual. Pengukuran TSS dilakukan dengan metode Titrasi (Alaerts dan Santika, 1987). Kertas Whattman no.41 dibilas dengan akuades, kemudian dioven pada suhu $105^{\circ} \mathrm{C}$ selama 1 jam, lalu didinginkan dengan desikator kabinet selama 15 menit. Kertas Whattman No. 41 tersebut ditimbang sebagai berat awal (x), selanjutnya diambil $50 \mathrm{ml}$ air sampel kemudian disaring dengan kertas Whattman No. 41 yang telah ditimbang tersebut. Filtrat yang tersaring beserta kertas Whattman no.41 tersebut dioven selama 1 jam pada suhu $105^{\circ} \mathrm{C}$. Kemudian dimasukkan ke dalam desikator kabinet selama 15 menit. Kertas Whattman ditimbang sebagai berat akhir (y). Besarnya TSS dihitung dengan rumus berikut.

$$
\text { TSS }=\frac{Y-X}{50} 10^{6} \mathrm{mg} . \mathrm{l}^{-1}
$$

Keterangan :

$\mathrm{Y}=$ berat kertas saring + residu

$\mathrm{X}=$ berat kertas saring

Pengukuran TDS dilakukan dengan metode Titrasi (Alaerts dan Santika, 1987). Kertas Whattman No. 41 dan cawan porselin dibilas dengan akuades, kemudian dioven pada suhu $105{ }^{\circ} \mathrm{C}$ selama 1 jam, lalu didinginkan dengan desikator kabinet selama 15 menit. Kertas Whattman No. 41 dan cawan porselin tersebut ditimbang, berat cawan porselen sebagai berat awal (x). Diambil $50 \mathrm{ml}$ air sampel kemudian disaring dengan kertas Whattman No. 41 yang telah ditimbang. Air yang lolos saringan dituang ke cawan porselin sebanyak $30 \mathrm{ml}$. Cawan porselin dioven pada suhu $105{ }^{\circ} \mathrm{C}$ selama 24 jam, lalu didinginkan dalam desikator 
selama 15 menit lalu ditimbang sebagai berat akhir (y). TDS ditentukan dengan rumus sebagai berikut:

$$
\text { TDS }=\frac{Y-X}{30} 10^{6} \mathrm{mg} . \mathrm{l}^{-1}
$$

Keterangan :

$\mathrm{Y}=$ berat mangkok porselin + residu

$\mathrm{X}=$ berat mangkok porselin

Kertas indikator pH diambil satu stik (lembar) dan dicelupkan ke dalam air sungai. Perubahan warna yang terjadi pada kertas $\mathrm{pH}$ dicocokkan dengan warna standar pada kemasan dan dicatat hasilnya.

Oksigen terlarut diukur menggunakan metode Winkler (APHA, 1992). Sampel air diambil dengan botol Winkler 250 ml (dengan hati-hati agar tidak ada gelembung udara) hingga penuh kemudian ditutup. Kemudian ditambahkan 1 $\mathrm{ml} \mathrm{MnSO}_{4}$ dan $1 \mathrm{ml} \mathrm{KOH-KI}$ menggunakan pipet seukuran, botol ditutup kembali. Botol dikocok perlahan sampai larutan $\mathrm{MnSO}_{4}$ dan $\mathrm{KOH}-\mathrm{KI}$ homogen dengan air dan kemudian didiamkan \pm 2 menit atau sampai timbul endapan berwarna coklat atau setidaknya sampai cairan supernatan berwarna jernih. Kemudian ditambahkan $\mathrm{H}_{2} \mathrm{SO}_{4}$ pekat sebanyak $1 \mathrm{ml}$ dengan pipet seukuran dan botol ditutup kembali. Botol dikocok perlahan atau dibolak-balik hingga semua endapan menjadi larut dan berwarna coklat kekuningan, kemudian diambil $100 \mathrm{ml}$ dengan menggunakan gelas ukur dan dituang ke dalam erlenmeyer. Indikator amilum ditambahkan 3-5 tetes hingga berwarna biru tua, lalu dititrasi dengan $\mathrm{Na}_{2} \mathrm{~S}_{2} \mathrm{O}_{3} 0,025 \mathrm{~N}$ hingga warna biru tersebut hilang/jernih. Jumlah titran yang digunakan dicatat dan dimasukkan ke dalam rumus untuk menghitung kadar oksigen terlarut.

$$
\text { DO }=\frac{1000}{100} \times \mathrm{p} \times \mathrm{q} \times 8 \mathrm{mg} . \mathrm{l}^{-1}
$$

Keterangan :

$\mathrm{p}=$ jumlah $\mathrm{Na}_{2} \mathrm{~S}_{2} \mathrm{O}_{3} 0,025 \mathrm{~N}$ yang digunakan dalam titrasi $(\mathrm{ml})$

$\mathrm{q}=$ normalitas larutan $(0,025 \mathrm{~N})$

$8=$ bobot setara dengan $\mathrm{O}_{2}$

Sampel air diambil dengan botol Winkler $250 \mathrm{ml}$ kemudian ditutup. Diambil $100 \mathrm{ml}$ menggunakan gelas ukur dan dituangkan ke dalam gelas erlenmeyer. Indikator PP ditambahkan sebanyak 3-5 tetes, jika berubah warna menjadi pink berarti $\mathrm{CO}_{2}$ tidak terdeteksi karena kadar yang terlalu kecil sehingga tidak perlu dititrasi. Jika tidak berubah kemudian dititrasi dengan $\mathrm{Na}_{2} \mathrm{CO}_{3}$ 0,01 $\mathrm{N}$ sampai larutan berubah warna menjadi pink. Jumlah titran yang digunakan dicatat, dimasukkan dalam rumus untuk menghitung kadar $\mathrm{CO}_{2}$ bebas.

$$
\text { Kadar } \mathrm{CO}_{2} \text { bebas }=\frac{1000}{100} \times \mathrm{p} \times \mathrm{q} \times 22
$$

Keterangan :

$\mathrm{p}=$ jumlah $\mathrm{Na}_{2} \mathrm{CO}_{3} 0,01 \mathrm{~N}$ yang digunakan dalam titrasi $(\mathrm{ml})$

$\mathrm{q}=$ normalitas larutan $(0,01 \mathrm{~N})$

22 = bobot setara dengan $\mathrm{CO}_{2}$

$\mathrm{BOD}_{5}$ diukur dengan metode Winkler (APHA, 1985). Sampel air diencerkan dengan tingkat pengenceran $10 \%$. Air pengencer terdiri dari larutan $\mathrm{FeCl}_{3}, \mathrm{CaCl}_{2}$, buffer fosfat dan $\mathrm{MgSO}_{4}$ masing-masing $1 \mathrm{ml}$ tiap liter air pengencer. Sampel yang telah diencerkan dimasukkan dalam 2 botol Winkler volume $250 \mathrm{ml}$. Botol Winkler pertama diperiksa kandungan oksigennya yang dinyatakan sebagai $\mathrm{DO}_{0}$ hari, sedangkan botol Winkler kedua diperiksa setelah 5 hari dan dinyatakan sebagai $\mathrm{DO}_{5}$ hari. Blanko yang digunakan adalah akuades dengan perlakuan sama seperti cara kerja untuk air sampel. Kandungan BOD dihitung dengan persamaan:

$$
\text { BOD5 }=\frac{(\mathrm{X} 0-\mathrm{X} 5)-(\mathrm{B} 0-\mathrm{B} 2)(1-\mathrm{P})}{P}
$$

Keterangan :

$\mathrm{X}_{0}=$ kandungan $\mathrm{O}_{2}$ terlarut sampel hari ke-0

$\mathrm{X}_{5}=$ kandungan $\mathrm{O}_{2}$ terlarut sampel hari ke-5

$\mathrm{B}_{0}=$ kandungan $\mathrm{O}_{2}$ terlarut blanko hari ke- 0

$\mathrm{B}_{2}=$ kandungan $\mathrm{O}_{2}$ terlarut blanko hari ke-5

$\mathrm{P}=$ faktor pengenceran

Pengukuran COD dilakukan dengan metode Titrasi (Alaerts dan Santika, 1987). Sampel air dan blanko berupa akuades sebanyak $10 \mathrm{ml}$ dituangkan ke dalam erlenmeyer berasah, lalu ditambahkan $5 \mathrm{ml}$ larutan $\mathrm{K}_{2} \mathrm{Cr}_{2} \mathrm{O}_{7}$ 0,25 $\mathrm{N}$ dan dikocok secara perlahan hingga homogen dan setelah itu dimasukkan 4 buah batu didih. Sampel tersebut ditambahkan $15 \mathrm{ml} \mathrm{H}_{2} \mathrm{SO}_{4}$ pekat. Setelah itu ditempatkan di kondensor dan dipanaskan selama 2 jam pada suhu $365^{\circ} \mathrm{C}$. Setelah 2 jam, kondensor dimatikan dan sampel ditunggu hingga dingin. Setelah dingin sampel diencerkan hingga 100 ml menggunakan akuades dan diteteskan indikator feroin sebanyak 4 tetes. Sampel dititrasi dengan larutan FAS (Fero Amonium Sulfat) sampai warna hijau-biru menjadi warna merah bata. Pemberian larutan dan titrasi pada blanko dilakukan dengan cara yang sama. Jumlah titran dicatat, dan dimasukkan dalam rumus sebagai berikut.

$$
\text { Kandungan COD }=\frac{a-b \times N \times 8000}{m l \text { sampel }}
$$

Keterangan :

$\mathrm{a}=\mathrm{ml}$ FAS yang digunakan pada titrasi blanko

$\mathrm{b}=\mathrm{ml}$ FAS yang digunakan pada titrasi sampel

$\mathrm{N}=$ normalitas larutan FAS

Sampel air sebanyak $50 \mathrm{ml}$ dipindahkan ke dalam tabung erlenmeyer $250 \mathrm{ml}$ dan ditambahkan $1 \mathrm{ml}$ larutan $\mathrm{ZnSO}_{4}$, dihomogenkan. Kemudian ditambahkan $\mathrm{NaOH} 6 \mathrm{~N}$ sampai timbul endapan putih. Sampel disaring menggunakan kertas Whattman no. 1, lalu ditambahkan 1-2 tetes reagen EDTA dan dihomogenkan. Sampel yang telah ditambahkan EDTA dipindahkan dalam tabung erlenmeyer $50 \mathrm{ml}$ dan ditambahkan reagen Nessler, kemudian dihomogenkan dan didiamkan selama 10 menit. Setelah itu untuk mengetahui absorbansinya diukur menggunakan spektrofotometer dengan panjang gelombang $425 \mathrm{~nm}$ dan digambar kurva absorbansinya yang dibandingkan dengan konsentrasi standar (garis kalibrasi). Kandungan amonia diukur dengan rumus sebagai berikut.

$$
\mathrm{Mg} / 1 \mathrm{NH}_{3}=\mathrm{mg} \mathrm{NH}_{3}-\mathrm{N} \text { yang dibaca dari kurva standar }
$$

Mengukur Silika (BSN, Metode SNI 1991;06-2477, 1991) dilakukan pada sampel air sebanyak $50 \mathrm{ml}$. Ditambahkan 1 ml HCl 1:1, ditambahkan $2 \mathrm{ml}$ Amonium Molybdate dan didiamkan selama 5 menit, kemudian ditambahkan $2 \mathrm{ml}$ Asam Oksalat. Kandungan silika air sampel diukur menggunakan spektrofotometer dengan panjang gelombang $410 \mathrm{~nm}$, kemudian hasil yang diperoleh dicatat.

Mengukur Orthofosfat (BSN, Metode SNI 06-6989.31, 2005) dilakukan pada sampel air sebanyak $50 \mathrm{ml}$. Sampel dimasukkan ke dalam erlenmeyer $50 \mathrm{ml}$, ditambahkan 1-2 tetes indikator pp dan $1 / 2$ tetes $\mathrm{NaOH}$ sampai merah muda kemudian ditambahkan $8 \mathrm{ml}$ reagen campuran (AMM Molybdat, K-Antimonil, $\mathrm{H}_{2} \mathrm{SO}_{4}$ dan asam ascorbik) ditempelkan kemulut erlenmeyer dan ditunggu 5 menit. Kandungan ortofosfat air sampel diukur menggunakan spektrofotometer dengan panjang gelombang $880 \mathrm{~nm}$.

Hubungan kelimpahan Diatom dan kandungan silika dapat dievaluasi menggunakan analisis deskriptif. Hal tersebut dilakukan dengan Analisa Regresi. 
Analisis regresi digunakan untuk menentukan hubungan antara kandungan silika dengan kelimpahan diatom. Menurut Sugiyono (2004) analisis regresi dapat dijelaskan melalui persamaan linier

$$
\mathrm{Y}=\mathrm{a}+\mathrm{bX}
$$

Keterangan :

$\mathrm{Y}=$ subyek variable dependen dalam hal ini yaitu kelimpahan diatom

$\mathrm{X}=$ subyek variable independen dengan nilai tertentu dalam hal ini yaitu kandungan silika.

$\mathrm{a}=$ harga $\mathrm{Y}$ bila $\mathrm{X}=0$

$\mathrm{b}=$ angka arah atau koefisien regresi yang menunjukan angka peningkatan atau penurunan variable dependen yang didasarkan pada variable independen

Analisis korelasi digunakan untuk menentukan besarnya pengaruh hubungan antara kandungan silika terhadap kelimpahan diatom yang dinyatakan dengan koefisien korelasi $(r)$, besarnya nilai $r=-1 \leq r \leq+1$. Tingkat varian pada kelimpahan diatom yang dipredisikan oleh hubungan antara kandungan silika dapat dijelaskan dengan nilai koefisien determinasi yaitu kuadrat dari koefisien korelasi $\left(\mathrm{r}^{2}\right)$. Untuk menentukan signifikansi terhadap koefisien determinasi yang didapatkan menggunakan uji $\mathrm{F}$.

\section{HASIL DAN PEMBAHASAN}

Pada penelitian ini kandungan silika terukur berkisar antara 112,62-175 mg.l-1 dengan rata-rata $146 \mathrm{mg.l}^{-1}$. Kandungan silika tertinggi terdapat pada stasiun IV yaitu 175 mg.l-1, sedangkan kandungan silika terendah terdapat pada stasiun V yaitu 112,62 mg.l-1. Turner (1980) dalam Widjaja et al., (1994) menyatakan bahwa apabila kandungan silika lebih kecil dari 0,5 mg.l-1 maka fitoplankton khususnya diatom tidak dapat berkembang dengan baik.

Tabel 2. Kandungan Rata-rata Silika di perairan Sungai pelus Kabupaten Banyumas

\begin{tabular}{lrrrrr}
\hline \multirow{2}{*}{ No Stasiun } & \multicolumn{3}{c}{ Kandungan Silika(mg.l-1 $)$} & Rerata Per \\
\cline { 3 - 5 } & & U1 & U2 & U3 & stasiun \\
\hline 1 & I & 268,00 & 76,00 & 94,30 & 146,00 \\
2 & II & 206,11 & 71,00 & 93,35 & 123,48 \\
3 & III & 207,00 & 110,45 & 102,00 & 140,00 \\
4 & IV & 295,00 & 130,89 & 99,00 & 175,00 \\
5 & V & 233,22 & 54,64 & 50,00 & 112,62 \\
\hline
\end{tabular}

Silika termasuk unsur hara makro yang sangat esensial yang diperlukan untuk pertumbuhan mikroalga. Beberapa algae, terutama diatom (Bacillariophyta), membutuhkan silika untuk membentuk frustule (dinding sel). Silika $\left(\mathrm{SiO}_{2}\right)$ merupakan partikel tersuspensi di perairan dalam bentuk silisic acid atau ion silikat, pada perairan alami silika berasal dari degradasi batuan yang mengandung silika (APHA, 1992). Lee (2008) menyatakan bahwa silika merupakan unsur kedua yang paling melimpah di kerak bumi tetapi sulit untuk larut dalam air.

Keberadaan silika pada perairan tidak menimbulkan masalah karena tidak bersifat toksik bagi makhluk hidup. Sumber silika dapat berasal dari tanah liat atau pasir yang tersuspensi di badan air. Doods (2002) mengatakan bahwa tanah liat mengandung silika dan tanah liat merupakan komponen primer dari sedimen dan kekeruhan air.
Pasir sebagian besar komponennya adalah silika dan juga merupakan komponen utama dari substrat dasar perairan.

Berdasarkan hasil penelitian ditemukan diatom benthik sebanyak 21 spesies. Kelimpahan rata-rata diatom bentik yang diperoleh selama penelitian berkisar antara 7.442-11.128 ind. $\mathrm{cm}^{-2}$, dengan ratarata sebesar 0-7861 ind.cm-2 (Tabel 3). Kelimpahan tertinggi secara berurutan adalah kelimpahan pada stasiun II 11.128 ind. $\mathrm{cm}^{-2}$, kelimpahan pada stasiun III 10.430 ind.cm ${ }^{-2}$, kelimpahan pada stasiun $\mathrm{V}$ yaitu 8.614 ind. $\mathrm{cm}^{-2}$, kelimpahan pada stasiun I yaitu 7.442 ind. $\mathrm{cm}^{-2}$ dan kelimpahan terendah berada pada stasiun IV yaitu 6.828 ind. $\mathrm{cm}^{-2}$ dengan kelimpahan relatif berkisar antara 0,11-17,68\% (Tabel 3). Tingginya kelimpahan ini dikarenakan adanya limbah penduduk dan limbah persawahan dari sisa-sisa pupuk yang dibuang ke sungai. Limbah yang mengandung unsur-unsur nitrat dan fosfat yang sangat dibutuhkan untuk pertumbuhan diatom. Nitrogen dan fosfor yang merupakan makro nutrien, keduanya sebagai nutrien pembatas bagi pertumbuhan fitoplankton (Suthers \& Rissik, 2008). Forsstrom (2006) menambahkan bahwa nutrien yang penting untuk pertumbuhan dan perkembangbiakan Chrysophyta, terutama diatom yaitu silika.

Spesies yang paling banyak ditemukan yaitu Diatoma sp. 7.861 ind. $\mathrm{cm}^{-2}$, yang diduga karena kandungan ortophosfat yang optimum (0,031-0,212 mg.l-1 $)$. Menurut Subarijanti (2003), perairan dengan kandungan fosfat berkisar antara 0,00-0,02 mg.l-1 banyak didominasi diatom. Faktor lain yang mendukung kelimpahan adalah suhu yang optimum. Menurut Sachlan (1982), diatom mempunyai toleransi yang luas terhadap suhu. Suhu yang optimum untuk pertumbuhan diatom menurut Werner (1977) adalah 20-30 ${ }^{\circ} \mathrm{C}$. Karakter-karakter yang dimiliki genus tersebut dapat digunakan sebagai indikator perairan. Hal ini sesuai dengan pernyataan Harding et al. (2005), genus Diatoma merupakan salah satu yang dapat digunakan sebagai indikator perairan.

Spesies kedua paling banyak ditemukan yaitu Navicula protractoides 7.752 ind. $\mathrm{cm}^{-2}$. Spesies ini mempunyai dinding silika yang berfungsi sebagai penguat tubuh dalam kondisi ekstrim. Menurut Kumar dan Singh (1982), Navicula memiliki dinding sel dari bahan silika yang berfungsi sebagai penguat sehingga dapat tumbuh meskipun dalam kondisi ekstrim. Navicula merupakan salah satu jenis yang digunakan sebagai indikator perairan yang kaya unsur hara (Whitton, 1975).

Spesies paling banyak ketiga yaitu Diatoma vulgare 6.070 ind. $\mathrm{cm}^{-2}$. Spesies ini memiliki penyebaran yang sangat luas serta mampu beadaptasi terhadap perubahan lingkungannya, sehingga sering ditemukan pada setiap stasiun pengambilan sampel. Hal tersebut sesuai dengan pernyataan Sachlan (1982) bahwa jenis-jenis dari divisi Chrysophyta mempunyai penyebaran yang sangat luas dan mampu hidup pada kondisi lingkungan yang ekstrim. 
Tabel 3. Kelimpahan Rata-rata dan Kelimpahan Relatif Diatom Bentik yang diperoleh Selama Penelitian di Perairan Sungai Pelus Kabupaten Banyumas

\begin{tabular}{|c|c|c|c|c|c|c|c|}
\hline \multirow{2}{*}{ Spesies/Divisio } & \multicolumn{5}{|c|}{ Kelimpahan (ind.cm-2) di masing-masing stasiun } & \multirow{2}{*}{ Jumlah } & \multirow{2}{*}{ KR (\%) } \\
\hline & I & II & III & IV & $\mathbf{V}$ & & \\
\hline Chrysophyta & & & & & & & \\
\hline 1 Cocconeis placentula & 51 & 0 & 0 & 0 & 0 & 51 & 0,11 \\
\hline 2 Cyclotella sp. & 0 & 232 & 0 & 1347 & 2707 & 4286 & 9,64 \\
\hline 3 Cymbella naviculiformis & 915 & 1547 & 109 & 0 & 483 & 3054 & 6,87 \\
\hline 4 Denticula tenuis & 483 & 232 & 51 & 109 & 51 & 926 & 2,08 \\
\hline 5 Diatoma sp. & 1946 & 1302 & 1572 & 1817 & 1224 & 7861 & 17,68 \\
\hline 6 Diatoma vulgare & 1411 & 728 & 2088 & 1482 & 361 & 6070 & 13,65 \\
\hline 7 Gomphonema sp. & 0 & 0 & 0 & 0 & 0 & 0 & 0 \\
\hline 8 Epithemia sp. & 0 & 1224 & 915 & 541 & 606 & 3286 & 7,39 \\
\hline 9 Fragilaria $s p$ & 0 & 1102 & 296 & 0 & 0 & 1398 & 3,14 \\
\hline 10 Frustulia rhomboides & 0 & 419 & 0 & 0 & 0 & 419 & 0,94 \\
\hline 11 Navicula protractoides & 1843 & 1779 & 1585 & 728 & 1817 & 7752 & 17,44 \\
\hline 12 N. placantula & 793 & 541 & 2088 & 361 & 296 & 4079 & 9,17 \\
\hline 13 Nitzschia actinastroides & 0 & 109 & 296 & 0 & 361 & 766 & 1,72 \\
\hline 14 N. acicularia & 0 & 541 & 0 & 0 & 361 & 902 & 2,02 \\
\hline 15 Pinnularia $s p$. & 0 & 0 & 232 & 51 & 0 & 283 & 0,36 \\
\hline 16 Surirella sp. & 0 & 296 & 1038 & 109 & 0 & 1443 & 3,24 \\
\hline 17 S. elegans & 0 & 0 & 109 & 0 & 296 & 405 & 0,91 \\
\hline 18 S. striatula & 0 & 0 & 0 & 232 & 0 & 232 & 0,52 \\
\hline 19 Synedra sp. & 0 & 51 & 51 & 0 & 0 & 102 & 0,22 \\
\hline 20 Tabellaria $s p$. & 0 & 606 & 0 & 0 & 0 & 606 & 1,36 \\
\hline 21 Gyrosigma sp. & 0 & 419 & 0 & 0 & 51 & 470 & 1,05 \\
\hline 22 Synedra cunningtoni & 0 & 0 & 0 & 51 & 0 & 51 & 0,11 \\
\hline Total Kelimpahan & 7.442 & 11.128 & 10.430 & 6.828 & 8.614 & 44.442 & \\
\hline
\end{tabular}

Tabel 4. Faktor Fisika dan Kimia yang Berperan Bagi Kehidupan Diatom

\begin{tabular}{|c|c|c|c|c|c|c|c|c|}
\hline \multirow{2}{*}{ No } & \multirow{2}{*}{ Parameter } & \multirow{2}{*}{ Satuan } & \multicolumn{5}{|c|}{ Stasiun } & \multirow{2}{*}{ Kisaran } \\
\hline & & & I & II & III & IV & $\overline{\mathbf{V}}$ & \\
\hline 1 & Suhu & ${ }^{0} \mathrm{C}$ & 19,7 & 25,5 & 29,1 & 28,4 & 29,4 & $19,70-29,40$ \\
\hline 2 & Kecepatan Arus & $\mathrm{m} \cdot \mathrm{dt}^{-1}$ & 0,35 & 0,41 & 0,48 & 1,12 & 0,49 & $0,35-1,12$ \\
\hline 3 & $\mathrm{pH}$ & & 7,00 & 7,00 & 7,00 & 7,00 & 7,00 & 7,00 \\
\hline 4 & TSS & mg.l-1 & 1,53 & 1,89 & 3,31 & 1,4 & 2,66 & $1,40-3,31$ \\
\hline 5 & TDS & mg.l-1 & 75,55 & 88,89 & 115,55 & 133,33 & 176,67 & $75,55-176,67$ \\
\hline 6 & DO & mg.l-1 & 8,46 & 8,23 & 7,53 & 7,36 & 5,93 & $5,93-8,46$ \\
\hline 7 & BOD & mg.l-1 & 2,91 & 2,6 & 2,3 & 3,24 & 3,18 & $2,30-3,24$ \\
\hline 8 & COD & mg.l-1 & 72 & 117,33 & 74,66 & 32 & 24 & $24,00-117,33$ \\
\hline 9 & Nitrat & mg.l-1 & 0,16 & 0,93 & 0,91 & 0,99 & 1,34 & $0,16-1,34$ \\
\hline 10 & OrthoFosfat & mg.l-1 & 0,063 & 0,031 & 0,038 & 0,212 & 0,049 & $0,031-0,212$ \\
\hline
\end{tabular}

Pengaruh antara silika dengan kelimpahan diatom dianalisis dengan analisis korelasi (Tabel 4). Besarnya pengaruh hubungan dinyatakan dengan $r$ (koefisien korelasi). Hasil perhitungan didapatkan $r$ sebesar 0,385 yang berarti terdapat hubungan linier sempurna secara langsung antara kandungan silika (x) dengan kelimpahan diatom (y) dari hasil analisis signifikansi terhadap koefisien determinasi didapatkan hasil $F_{\text {hit }} \geq F_{\text {tabel yang berarti terdapat hasil }}$ yang signifikan atau hubungan yang sangat nyata antara kandungan silika dengan kelimpahan diatom.

Hubungan antara kandungan silika dengan kelimpahan diatom rendah ditunjukkan dengan $\mathrm{R}^{2}$ (koefisien determinasi) yaitu sebesar 0,38 atau 38\%. Jadi kelimpahan diatom dipengaruhi oleh silika sebesar 38\% dan sisanya ditentukan oleh faktor lain.

Hubungan antara Kandungan silika dengan kelimpahan diatom di perairan Sungai Pelus dianalisis dengan menggunakan analisis regresi. Dari hasil analisis regresi dapat diketahui hubungan antara kandungan silika dengan kelimpahan diatom, yang ditunjukkan melalui persamaan garis linier $\mathrm{y}=$ $15.600,362-48,152(\mathrm{x})$.

Rendahnya pengaruh kandungan silika dengan kelimpahan diatom berkaitan dengan dimanfaatkannya silika secara langsung oleh diatom. Bellinger and Sigee (2010), menyatakan bahwa silika sangat dibutuhkan untuk pembentukan dinding sel pada diatom dan hal tersebut tergantung pada tersedianya silika yang terlarut pada sebuah perairan.

Tabel 5. Hubungan Kelimpahan Diatom dengan Kandungan Silika di Perairan Sungai Pelus Banyumas

\begin{tabular}{rl}
\hline Variabel tergantung & Kelimpahan Diatom \\
Variabel bebas & Silika \\
Persamaan regresi tunggal & $\mathrm{Y}=15600,362-48,152(\mathrm{X})$ \\
$\mathrm{r}^{2}$ & 0,385 \\
$\mathrm{R}$ & 0,62 \\
\hline
\end{tabular}

Berdasarkan hasil pengamatan terhadap parameter faktor Fisika-Kimia, suhu perairan Sungai Pelus Kabupaten Banyumas berkisar 19,7-29,40 ${ }^{\circ} \mathrm{C}$. Suhu suatu badan air dipengaruhi oleh musim, 
lintang, ketinggian dari permukaan laut, waktu dalam hari, sirkulasi udara, penutupan awan dan aliran serta kedalaman badan air. Organisme akuatik memiliki kisaran suhu tertentu yang disukai bagi pertumbuhannya, misalnya Chlorophyta dan diatom akan tumbuh dengan baik pada kisaran suhu berturut-turut $30-35{ }^{\circ} \mathrm{C}$ dan $20-30{ }^{\circ} \mathrm{C}$, sedangkan Cyanophyta lebih dapat bertoleransi terhadap kisaran suhu yang lebih tinggi dibandingkan dengan Chlorophyta dan Diatom (Haslam, 1995).

Arus sebagai faktor pembatas pada aliran air ditentukan oleh kemiringan, kedalaman dan kelebaran dasarnya (Odum 1971). Menurut Welch dan Lindell (1980), terdapat lima kategori arus yaitu arus yang sangat lambat (kurang dari 0,10 m.detik ${ }^{-1}$ ), lambat $\left(0,10-0,25\right.$ m.detik $\left.{ }^{-1}\right)$, sedang $(0,25-0,50$ m.detik $\left.{ }^{-1}\right)$, cepat $\left(0,50-1\right.$ m.detik $\left.^{-1}\right)$, dan sangat cepat (lebih dari 1 m.detik ${ }^{-1}$ ). Kecepatan arus diperairan Sungai Pelus Kabupaten Banyumas berkisar antara 0,35-1,12 m.detik ${ }^{-1}$ dengan rata-rata 0,57 m.detik ${ }^{-1}$ (Tabel 4) sehingga termasuk dalam kategori sedang sampai sangat cepat. Menurut Odum (1971), Arus perairan dapat menentukan penyebaran gas dalam air, misalnya oksigen terlarut semakin cepat kecepatan arus dan debit air, semakin cepat dan semakin luas penyebaran kualitas air yang terjadi.

Derajat keasaman atau pH air sangat dipengaruhi oleh karbondioksida sebagai substansi asam. Menurut Pescod (1973) nilai pH dipengaruhi oleh beberapa faktor antara lain aktivitas biologi misalnya fotosintesis dan respirasi organisme. Hasil pengukuran $\mathrm{pH}$ pada semua stasiun di perairan Sungai Pelus adalah 7 (Tabel 4). Menurut Effendi (2003), sebagian besar biota akuatik sensitif terhadap perubahan $\mathrm{pH}$ dan menyukai nilai $\mathrm{pH}$ sekitar 7-8,5 sehingga, pH di perairan Sungai Pelus Kabupaten Banyumas masih mendukung kehidupan diatom.

Total Suspended Solid (TSS), dapat berupa bahan organik, plankton, lempung dan lainnya (Alaerts dan Santika, 1987). Nilai TSS di perairan Sungai Pelus Kabupaten Banyumas berkisar antara 1,4-2,66 mg.l${ }^{1}$ dengan rata-rata sebesar 2,16 mg.l ${ }^{-1}$ (Tabel 4). Hasil tersebut masih di bawah kriteria baku mutu air kategori kelas III yang terdapat pada PP No. 82 Tahun 2001 yang menyatakan bahwa, nilai TSS tidak boleh lebih dari 400 mg.l-1 $^{-1}$ Effendi (2003) mengatakan bahwa TSS terdiri atas lumpur dan pasir halus serta jasad-jasad renik, terutama disebabkan oleh kikisan tanah atau erosi tanah yang terbawa ke badan air.

Total Dissolved Solid (TDS) di perairan Sungai Pelus Kabupaten Banyumas berkisar antara 75,55-

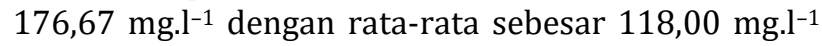
(Tabel 4). Hasil tersebut masih dibawah kriteria baku mutu air kategori kelas III yang terdapat pada PP No. 82 tahun 2001 yang menyatakan bahwa, nilai TDS tidak boleh lebih dari 1000 mg.l-1 . Berdasarkan hal tersebut maka dapat dikatakan nilai TDS di perairan Sungai Pelus memenuhi untuk pembudidayaan ikan air tawar, peternakan dan air untuk mengairi pertanaman.
Kandungan oksigen terlarut yang mendukung kehidupan organisme perairan harus lebih besar dari 2 mg.l $^{-1}$ (Pescod, 1973). Selanjutnya Boyd (1988) menyatakan bahwa, plankton dapat tumbuh dengan baik pada kondisi perairan dengan nilai oksigen terlarut $>5 \mathrm{mg}^{-1}{ }^{-1}$. Hasil pengukuran oksigen terlarut di perairan Sungai Pelus Kabupaten Banyumas berkisar antara 5,93-8,46 mg.l ${ }^{-1}$ dengan rata-rata sebesar 7,50 mg.l-1 (Tabel 4). Berdasarkan hal tersebut, maka oksigen terlarut di Perairan Sungai Pelus Kabupaten Banyumas mendukung untuk pertumbuhan fitoplankton.

Biochemical Oxygen Demand (BOD 5 ) merupakan metode yang sederhana untuk mengukur total kandungan bahan organik dan kemikalia lain yang bereaksi spontan dengan oksigen yang tersedia untuk organisme (Doods, 2002). Hasil pengukuran BOD yang diperoleh di perairan Sungai Pelus Kabupaten Banyumas berkisar antara 2,3-3,24 mg.l-1 (Tabel 4). Hasil tersebut masih dibawah baku mutu air kategori kelas III yang terdapat pada PP No. 82 tahun 2001 yang menyatakan bahwa, nilai $\mathrm{BOD}_{5}$ tidak boleh lebih dari 6 mg.l-1. Berdasarkan hal tersebut maka perairan Sungai Pelus Kabupaten Banyumas masih memenuhi untuk pembudidayaan ikan air tawar, peternakan dan air untuk mengairi pertanaman.

Bahan pencemar organik yang tidak dapat diuraikan oleh organisme namun diuraikan dengan bahan kimia diukur dengan Chemical Oxygen Demand (COD). Nilai COD yang diperoleh selama penelitian di perairan Sungai Pelus Kabupaten Banyumas berkisar 24-117,33 mg.l-1 (Tabel 4). Stasiun I sebesar 72 mg.l-1, stasiun II sebesar 117,33 mg.l-1, stasiun III sebesar 74,66 mg.l ${ }^{-1}$, stasiun IV sebesar 32 mg.l-1 dan stasiun V sebesar 24 mg.l-1. Kandungan COD yang diperoleh dibandingkan dengan PP No. 82 tahun 2001. Menurut PP No. 82 Tahun 2001, stasiun I dan stasiun III masuk dalam baku mutu kelas IV tidak boleh lebih dari 100 mg.l-1 ${ }^{-1}$ stasiun IV masuk dalam baku mutu kelas III karena tidak boleh lebih dari 50 mg.l-1 dan stasiun $\mathrm{V}$ masuk dalam baku mutu kelas II karena tidak boleh lebih dari 25 mg.l $\mathrm{l}^{-1}$.

Nitrat adalah bentuk utama nitrogen di perairan alami dan merupakan nutrien utama bagi pertumbuhan tanaman dan algae (Effendi, 2003). Hasil pengukuran nitrat di perairan Sungai Pelus berkisar 0,16-1,34 mg.l-1 (Tabel 4). Menurut Mackentum (1969) dalam Yuliana et al., (2012) untuk pertumbuhan optimal fitoplankton memerlukan kandungan nitrat pada kisaran 0,9-3,5 mg.l-1 .

Ortofosfat merupakan bentuk fosfor yang dapat dimanfaatkan secara langsung oleh tumbuhan akuatik untuk pertumbuhan fitoplankton. Biasanya terdapat dalam jumlah yang sedikit sehingga sering menjadi faktor pembatas bagi pertumbuhan fitoplankton (Warsa et al., 2006). Hasil pengukuran ortofosfat di perairan Sungai Pelus Kabupaten Banyumas berkisar antara 0,031-0,212 mg.l-1 dengan rata-rata sebesar 0,079 mg.l-1 (Tabel 4). Menurut Mackentum (1969) dalam Yuliana et al., (2012), untuk pertumbuhan 
optimal fitoplankton memerlukan kandungan ortofosfat pada kisaran 0,09-1,80 mg.l-1 . Bruno et al., (1979) dalam Sumardianto (1995), menambahkan bahwa kandungan ortofosfat yang optimal bagi pertumbuhan fitoplankton adalah 0,27-5,51 mg.l-1 dan jika kandungannya kurang dari 0,02 mg.l-1 maka akan menjadi faktor pembatas. Berdasarkan hasil yang diperoleh menunjukkan bahwa kandungan ortofosfat di perairan Sungai Pelus Kabupaten Banyumas masih baik untuk pertumbuhan fitoplankton.

\section{KESIMPULAN DAN SARAN}

Kesimpulan yang dapat diambil dari penelitian adalah: kandungan silika di perairan Sungai Pelus Kabupaten Banyumas berkisar antara 112,48-175 mg.l-1 dengan rata-rata sebesar $146 \mathrm{mg}^{-1} \mathrm{l}^{-1}$; kelimpahan total diatom bentik sebesar 44.442 ind.cm ${ }^{2}$, kelimpahan paling tinggi pada stasiun II yaitu 11.128 ind. $\mathrm{cm}^{-2}$, kelimpahan terendah berada pada stasiun IV yaitu 6.828 ind. $\mathrm{cm}^{-2}$; dan hubungan antara kandungan silika dengan kelimpahan diatom adalah rendah ditunjukkan dengan R2 (koefisien determinasi) sebesar 0,38 atau $38 \%$. Jadi kelimpahan diatom dipengaruhi oleh silika sebesar 38\% dan sisanya ditentukan oleh faktor lain.

Dari hasil penelitian kondisi kualitas air perairan Sungai Pelus perlu dipertahankan dengan mengendalikan pembuangan sampah domestik dari kegiatan masyarakat di sepanjang Sungai Pelus. Sehingga kelestarian lingkungan dapat terjaga.

\section{DAFT AR REFERENSI}

Alaerts GA, Santika SS. 1987. Metoda Penelitian Air. Surabaya: Usaha Nasional.

APHA (American Public Health Association). 1985. Standard Method for the Examination of Water and Waste Water $12^{\text {th }}$ Edition. Washington DC : APHA-AWWA-WPCF.

APHA (American Public Health Association). 1989. Standard Method for the Examination of Water and Waste Water $12^{\text {th }}$ Edition. , Washington DC: APHA-AWWA-WPCF.

APHA. (American Public Health Association). 1992. Standard Method for the Examination of Water and Waste Water $12^{\text {th }}$ Edition. Washington DC: APHA-AWWA-WPCF.

Aprisanti R, Mulyadi A, Siregar SH. 2013. Struktur Komunitas Diatom Epilitik Perairan Sungai Senapelan Dan Sungai Sail, Kota Pekanbaru. Jurnal lingkungan. ISSN 1978-5283.

Badan Standarisasi Nasional. 1991‥ Air dan Limbah: SNI 06-25031991. Jakarta.
Badan Standarisasi Nasional. 2005․ Air dan Limbah: SNI 06-25032005. Jakarta.

Bellinger EG, Sigee DC. 2010. Freshwater algae: Identification and us as bioindicators $1^{\text {st }}$ ed. Wiley-Blackwell: Oxford.

Boyd CE. 1988. Water Quality in Warmwater Fish Pond. Forth Printing. Alabama USA: Agricultural Experiment Station Auburn University.

Davis. 1955. The Marine and Fresh-Water Plankton. Chicago: Michigan State Universitas Press.

Doods WE. 2002. Freshwater Ecology : Concepts and Environmental Applications. San Diego: Academic Press.

Effendi H. 2003. Telaah Kualitas Air Bagi Pengelolaan Sumber Daya dan Lingkungan Perairan. Yogyakarta: Kanisius.

Forsstrom L. 2006. Phytoplankton Ecology of Subarctic Lakes in Finnish Lapland. Helsinki: Departement of Biological and Environmental Sciences Division of Aquatic Sciences University of Helsinki.

Harding WR, Archibaid CGM, Taylor JC. 2005. The Relevance of Diatoms for Water Quality Assessment in South Africa: A Position Paper. http://www.wrc.org.za

Haslam SM. 1995. Biological Indicators of Freshwater Pollution and Enviromental Management. London: Elsevier Applied Science Publisher.

Lee RE. 2008. Phycology $4^{\text {th }}$ Edition. New York: Cambrigde University Press xii $+547 \mathrm{hlm}$.

Odum EP. 1971. Fundamental Of Ecology 3rd Edition. Philadelphia: W. B. Saunders Company.

Pescod MB. 1973. Investigation of Rational Effluent and Stream Standard for Tropical Countries. Bangkok: Enironmental Engineering Division Asian Institute Technology.

Sachlan M. 1982. Planktonologi. Semarang: Fakultas Peternakan dan Perikanan Universitas Diponogoro.

Subarijanti HU. 2003. Faktor Lingkungan yang Mempengaruhi Pertumbuhan Plankton. Jakarta: Kumpulan Jurnal Perikanan. LON. URL:http://digilib.brawijaya.ac.id. 12 Maret 2016.

Sugiyono. 2004. Statistika Untuk Penelitian. Bandung: Alfabeta.

Sumardiato. 1995. Struktur Komunitas Fitoplankton Di Perairan Teluk Pelabuhan Ratu Jawa Barat. Bogor: Program Studi Managemen Sumber Daya Perairan. Fakultas Perikanan Institut Pertanian Bogor. 57p.

Suthers IM, Rissik D. 2008. Plankton: A Guide to their Ecology and Monitoring for Water Quality. Collingwood: CSIRO.

Warsa A, Lismining PA, Adriani SNK. 2006. Hubungan Nutrien (N dan P) terhadap Kelimpahan Fitoplankton di Waduk Koto Panjang, Provinsi Riau. Jatiluhur: Jurnal Prosiding Seminar Nasional Ikan IV.

Welch EB, Lindell T. 1980. Ecological Effect of Waste Water. Cambridge New York: Cambridge University Press.

Werner D. 1977. The Biology of Diatoms. Botanical Monograph, Volume 13. London: Blackwell Scientific Publication.

Whitton BA. 1975. River Ecology. London: Blackwell Scientific Publication.

Yuliana, Enan M, Adiwilaga, Harris E, Pratiwi NTM. 2012. Hubungan antara kelimpahan fitoplankton dengan parameter fisika kimiawi perairan di teluk Jakarta. Jurnal Akuatika. 3(2): 169179. ISSN 0853-2523. 